The research programme of the Institute covers a vast field, including the study of the chemical structure and properties of cellulose and polysaccharides, physico-chemical and chemical engineering investigations, for example, physico-chemical studies of paper-making fibres and flow and aggregating properties of suspensions, pulping and bleaching studies, disposal of waste liquor, paper formation, instrumentation and pulp and paper testing, analytical methods and the application of photography and microscopy in research. Thus, the Institute acts as a centre for fundamental research, supplementing the research organizations of individual companies. It stimulates and assists in the postgraduate training of students of McGill University, who are working for higher degrees in science and engineering, especially students whose theses deal with subjects of interest to the industry. Two hundred and fifty Ph.D. students have participated in this programme over the years, including a large number of students of chemistry and some chemical and mechanical engineers; it is hoped that in future students of physics, biophysics and biochemistry and biology will increasingly participate.

The Institute also conducts research at the request of individual companies, groups of companies and other sponsors in allied industries.

At the same time, the Institute acts as a clearing house and distribution centre for technical and scientific information, which is published in the form of monographs, bibliographies, translations, and critical reviews. Work carried out at the Institute is published in technical reports and articles in the periodical literature.

The different aspects of the work being done at the Institute were fully taken into account when planning the new building. Two-story blocks house the department of physics, physical measurement and electron microscopy; the mechanical engineering development sections with the adjacent chemical pulping pilot plant; the department for woodlands research, chemical pulping and fibre research, photography and microscopy and chemical analytical services, etc. ; there are a refiner and stock-preparation building and a bleaching and small-scale pulping laboratory together with all the ancillary services such as woodworking, sheet metal and pipe-fitting shops, engineering offices, control laboratories, ad ministrative offices with the branch library and a printing and duplicating shop. The buildings were designed to permit unrestricted expansion of any major saction without interference with any other, this requirement being met by arranging the building in four wings each of which houses a particular type of operation. The design also permits working space to be redistributed both horizontally and vertically.

To work in buildings specially designed for the purpose will greatly assist the staff of the Institute in carrying out their investigations, and all workers in the industry can thus look forward to receiving an ever-increasing flow of valuable data and information.

S. LAMMLE

\title{
SCIENCE AND CIVILIZATION
}

TN his Sir Henry Simpson Newland Oration before $I$ the Australian Medical Congress at Hobart on March 5, now published in the Australian Journal of Science $(20,251 ; 1958)$, the Prime Minister of Australia, the Right Hon. R. G. Menzies, dealing with "Modern Science and Civilization", examined the place of science, including military science, in modern society. Great talent in science is not the monopoly of any one country, and Mr. Menzies, agreeing that the U.S.S.R. is training a greater proportion of its population in applied science than is any other country, pointed out that the Soviet Union could conscript young men and women into science at will and that there was reason to believe that Soviet technological man-power was excessively concentrated upon military production. The Soviet achievement with artificial Earth satellites should therefore be regarded with a sense of balance and not as a tragedy. Even if some ultimate military purpose lies behind the recent exercises, it simply means that the statesmen of the free world must seek both to maintain such a power of destruction in war as would deter aggression and also continue their efforts to persuade the Communist Powers that the immense possibilities of applied science should be increasingly diverted to the service of the peaceful needs of men and women.

A main theme of Mr. Menzies's address was to emphasize the need for a balanced judgment and to show how easily our own standards of civilization could be distorted. Scientists, he remarked, are not a race apart. They are citizens, bound to a social consciousness and social duties, and cannot, any more than non-scientists, stand apart from the great moral issues. The liberty of the scientist to pursue his chosen study is part of that great structure of self-governing and self-disciplined freedom which the institutions of the democratic world had painfully but persistently developed. That liberty is under challenge, and the scientist has a special interest and responsibility to share in its defence. Natural philosophy cannot make its best contribution to life unless accompanied by a moral and mental philosophy to give it balance. It would be calamitous for the specialist to contract out of the formulation and expression of a social consciousness which recognizes the paramount need to preserve the spirit and institutions of freedom.

After referring to some of the achievements in research of the free peoples, besides which those of the Communist world are insignificant, Mr. Menzies insisted on the need to take long views if civilization is to advance. It is a short answer to the Soviet achievements in the Sputnik field to suggest that we need only produce more and better scientists. The crucial question is for what purpose such scientists are to be used. We must recognize the danger of adopting Soviet methods to achieve Soviet results. Provision for scientific defence is for us solely a means of preserving democratic freedom and civilized individual rights. If such provision came to be regarded not as a free national effort but as something requiring the abandonment of freedom and acceptance of authoritarian control, we would have abandoned the case against Communism in the very effort to maintain that case. 
Pointing out further that without more scientists and more scientific research the material future of the free world could not be assured and enlarged, Mr. Menzies also referred to the danger here of confusing ends with means. Whether scientific advance means human salvation or a new and complicated form of technological slavery depends on our character, our broad intelligence and our wise and understanding judgment. We must be ready to meet aggression with purpose as well as vigour, but our social policies and particularly our educational policies must be so devised as to encourage sanity and responsibility, and discover blundering accident. Psychologically, the true answer to the threat of war must be found in the improvement of the nature of man himself. The true end to be served is the enlargement of the human mind and spirit. We need more scientists, but also more scholars; more scholarly scientists; more scientific scholars; more historians and philosophers and poets. If science is truly to serve the cause of civilization it will be because the people who use the advances of science have grown to use them in a civilized way. Not all the most brilliant successes in laboratories and factories and fields would make a nation great in the eye of history if it had failed to enthrone the human spirit and to set about it knowledge, and justice, and patience, and understanding.

\section{RADIO RESEARCH, 1957}

$\mathrm{W}$ HILE research work devoted to various aspects of radio wave propagation is vital and should continue, it is recommended by the chairman of the Radio Research Board in his annual report* that the research programme of the Department of Scientific and Industrial Research Radio Research Station at Slough during the next five years should be broadened in scope, to ensure that experience is gained and progress made with other important topics. So far as possible, new fields of research should bear directly on practical applications, and examples include molecular amplifiers and oscillators, and the design and properties of microwave aerials. The radio transmissions from artificial Earth satellites, orbiting so that the source is sometimes within and sometimes above the ionosphere, already have provided a valuable new tool for examining ionospheric propagation, and frequency and directional measurements on the first two U.S.S.R. satellites were made at Slough. More accurate position data for the satellites are awaited before a full analysis of the results obtained is possible.

The work of the Radio Research Station is described in detail in the report of the Director, special emphasis having been given to items directly connected with the International Geophysical Year. In addition to the ionospheric observatories at Inverness, Port Stanley (Falkland Islands), Singapore and Slough, equipment designed or built at the Radio Research Station has been in operation at Halley Bay (Antarctica), Ibadan (Nigeria) and Port Lockroy (Grahamland). The Station has also been designated one of the four World Data Centres for the collection of all International Geophysical Year ionospheric data, the others being at Boulder (Colorado), Moscow and Tokyo. Data from about one hundred stations are sent directly to Slough, while those from some two hundred other stations arrive through the other three Centres.

Routine measurements over the current sunspot maximum period have yielded the highest monthly mean values of $F 2$ critical frequency ever recorded over twenty-six years. This experience suggests that in considering the allocation of appropriate frequencies for short-distance radio communication, a frequency of $60 \mathrm{Mc} . / \mathrm{s}$. may be taken as the upper limit ever likely to be used in normal $F$-region

* Department of Scientiflc and Industrial Research, Radio Research 1957: The Report of the Radio Research Board and the Report of the Director of Radio Research. Pp. iv $+43+4$ plates. (London : H.M. Stationery Office.) $3 s .6 d$, net. propagation. Work has continued on the selection of a suitable ionospheric index of solar activity, primarily as an aid to forecasting propagation conditions. A preliminary investigation suggests that it might be possible to produce a permanent set of charts which would give the critical frequency at any point in the world for any phase of the sunspot cycle (defined in terms of the ionospheric index of solar activity), and which ultimately should render many of the current routine ionospheric measurements unnecessary.

Work on oblique-incidence radio propagation in the high-frequency and very high-frequency bands has continued. An investigation is being made into a possibility that commercial use may be made of the observed lateral deviations of the propagation direction from the great circle path for frequencies of the order of $20 \mathrm{Mc} / \mathrm{s}$. when the latter mode has faded out. This phenomenon is not fully understood, but is thought to be due to some form of ground scattering. The value of the plan-position-indicator 'back-scatter' technique in the investigation of propagation modes to long distances is now established, and experiments are being made to compare the field-strength for forward propagation on a frequency of $17 \mathrm{Mc}$./s. with that for scatter reception from the same range. Another field of investigation is the forward-scattering of very high-frequency signals in the $E$-region, and associated with this form of propagation are the strong momentary enhancements of signal which are attributed to reflexions from sporadic meteors.

Long-distance 'scatter links' for ultra high frequencies, by which communication is obtained through forward scatter in the troposphere, are also being investigated at the Radio Research Station. Experiments are in progress on frequencies of 53 , 1,370 and 3,500 Mc./s. used over different path. lengths, with the view of clarifying the problem of whether the propagation is maintained as a result of random fluctuations of refractive index caused by turbulence throughout the whole troposphere, or is due to variations of refractive index in relatively restricted layers of the troposphere. $\mathrm{As}$ an aid to this study, direct measurements of tropospheric refractive index have been initiated and have so fax yielded encouraging results. Work has continued on the measurement of atmospheric radio noise, and equipment has been developed for routine use during the International Geophysical Year for measuring 